\title{
Photocatalytic Oxidation of Sulfite to Sulfate in the Presence of Yellow Sand
}

\author{
Sadamu YAMAGATA*, Masaaki NishiJo ${ }^{\dagger}$, Naoto MurAo, Sachio OHTA \\ and Isao MIZOGUCHI
}

Received April 19, 1993 ; Accepted September 2, 1993

\section{INTR,ODUCTION}

Acid rain, which causes great ecological damage, is one of the most serious environmental problems in the world today 1). Acid rain consists of sulfuric acid and nitric acid produced by the oxidation of sulfur dioxide and nitrogen oxides in the atmosphere. Although the oxidation processes of these precursors are believed to be a hydroxyl radical type gas phase reaction and liquid phase reactions with hydrogen peroxide and ozone 2), other oxidation processes have also been proposed. For example, some metal ions 3 ) and the leachate from free fall atmospheric dust 4) catalyze the oxidation of sulfite by means of dissolved oxygen in the liquid phase; iron oxide 5), zinc oxide and titanium dioxide ${ }^{6}$ ) photocatalyze the oxidation of sulfite and nitrous anion in aqueous solution; and flyash and soil photocatalyze the oxidation of sulfur dioxide adsorbed on them 7).

Some reports suggested that photocatalytic reactions contribute to atmospheric chemistry other than sulfite oxidation, e.g. production of carbon dioxide ${ }^{8)}$ and hydrogen peroxide ${ }^{9}$ ). These studies used natural soil or sand as photocatalysis. However, not much attention have been paid whether or not those photocatalysts actually exist in the atmosphere. Thus the photo

Department of Sanitary Engineering, Faculty of Engineering, Hokkaido University (North 13 West 8 , Sapporo, 060, Japan)

† Present address: Technology Development Division, Atomic Energy Bureau, Science and Technology Agency (21 Kasumigaseki 2, Chiyoda-ku, 100, Tokyo, Japan).

Key Words: Photocatalysis, Yellow Sand, Sulfite Oxidation, Acid Rain catalysis by soil aerosol in the atmosphere are still ambiguous although photocatalysis by soil or sand on the ground surface has been confirmed.

In this note, we first demonstrate possible contribution of photocatalytic reaction by yellow sand dust to the acid rain formation in the atmosphere. Yellow sand dust is the most common soil aerosol in Japan ${ }^{10)}$ and the Western North Pacific Ocean ${ }^{11)}$ which comes from the arid area in China. At first we compared the elemental and crystallographic features of yellow sand sampled from the ground with the reported date 12) of the yellow sand dust sampled in the atmosphere above Japan; then we investigated the photocatalytic activity of the yellow sand toward sulfite oxidation.

\section{EXPERIMENTAL}

Yellow sand sampled from the ground in the Jin-zhong basin in the middle of the Shanxi province, China was characterized by its metal components and crystallographic features using atomic absorption spectrometry with NIPPON JARELL ASH AA8500 and using X-ray diffraction with TOSHIBA $\mathrm{ME}-412 \mathrm{C}$.

Before the experiments the yellow sand was rinsed with distilled water and filtered with a cellulose nitrate membrane filter (Advantec, pore size $1.0 \mu \mathrm{m}$ ) several times. The concentration of sulfate anion in the filtrate was analyzed using ion chromatography (YOKOKAWA IC $-\mathbf{1 0 0}$, SAM125 column)

The UV - VIS diffuse reflectance spectrum of yellow sand was measured using a HITACHI 150-20 spectrophotometer with an integration sphere (HITACHI 150-0902). 
The photocatalytic activity of the yellow sand was examined in an aqueous solution. This is because yellow sand dust is known to act as the main snow forming ice nucleus ${ }^{13}$ ) above Japan; this snow melts and becomes rain drops. The yellow sand $(30 \mathrm{mg}$ ) was dispersed in $20 \mathrm{ml}$ of the aqueous solution of sodium sulfite $\left(0.5 \mathrm{mmol} / \mathrm{dm}^{3}\right)$ using ultrasonication. The suspension in a Pyrex tube was inserted into one of the slots of a round turntable and irradiated with an $\mathrm{Hg}$ lamp (TOSHIBA, SHL-100UVQ) situated at the center of the turntable. The Hg lamp emits light which has several strong emission lines from 300 to $600 \mathrm{~nm}$; none of the emission lines are shorter than $250 \mathrm{~nm}$. The concentrations of sulfite and sulfate anions were analyzed using ion chromatography. Iron oxide (5 mg, Wako Pure Chemical Industries) was used as a reference photocatalyst.

\section{RESULTS AND DISCUSSION}

Table 1 shows the metal components of the yellow sand analyzed by atomic absorption spectrometry. This result is in accordance with the analyses of yellow sand dust collected above Japan and yellow sand sampled in China 12) but the concentration of $\mathrm{Na}$ is several times smaller than the reported values. Figure 1 represents the XRD pattern of the yellow sand, which indicates that the yellow sand contains quartz, calcite and several clay minerals. This result is also consistent with the crystallographic analysis of the yellow sand dust collected above Japan 12). From these results we concluded that this yellow sand can be used in place of yellow sand dust above Japan which is blown from China.

The concentration of sulfate anion adsorbed on the yellow sand was much less than that of the reactant in the following photocatalytic experiment, i.e. sulfite anion.

Figure 2 shows the diffuse reflectance spectra of the yellow sand and iron oxide. From the spectrum of the yellow sand it was confirmed that the yellow sand absorbs the photons not only from the light source in this study but also those from the sun.

Figure 3 represents the time profiles of the
Table 1 Metal components of yellow sand (wt\%).

\begin{tabular}{cccccccc}
\hline $\mathrm{Si}$ & $\mathrm{Al}$ & $\mathrm{Na}$ & $\mathrm{Mg}$ & $\mathrm{Ca}$ & $\mathrm{Mn}$ & $\mathrm{K}$ & $\mathrm{Fe}$ \\
28.1 & 5.26 & 0.39 & 0.92 & 4.69 & 0.06 & 1.39 & 2.90 \\
\hline
\end{tabular}

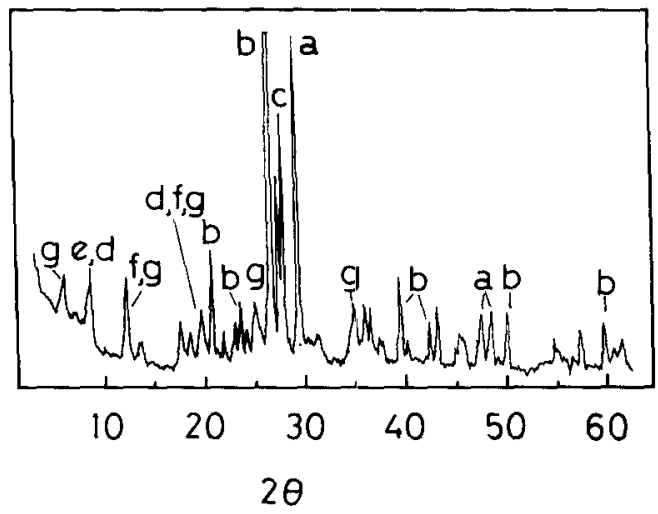

Fig. $1 \mathrm{X}$ ray diffraction pattern of the yellow sand. a: calcite; b: quartz; c: feldspar; d: illite; e: halloysite; ft kaolinite; g: chlorite.

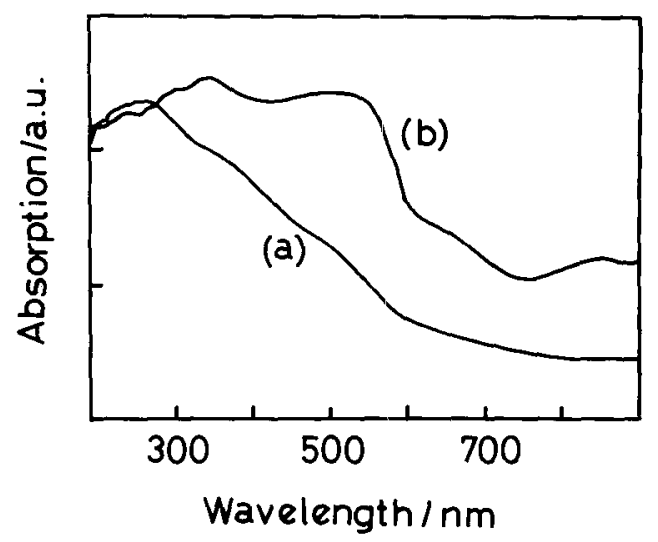

Fig. 2 Diffuse reflectance spectra of the yellow sand (a) and iron oxide (b).

concentrations of sulfite anion, sulfate anion and their sum during the UV irradiation in the presence of yellow sand (upper) and iron oxide (lower). In both cases sulfite anion decreased and sulfate anion increased monotonously with their total concentration remaining constant. When the sample containing yellow sand was not exposed to light, sulfite oxidation was not observed at room temperature. On the other hand under UV irradiation in the absence of catalysts sulfite anions were oxidized to sulfate anion which may 


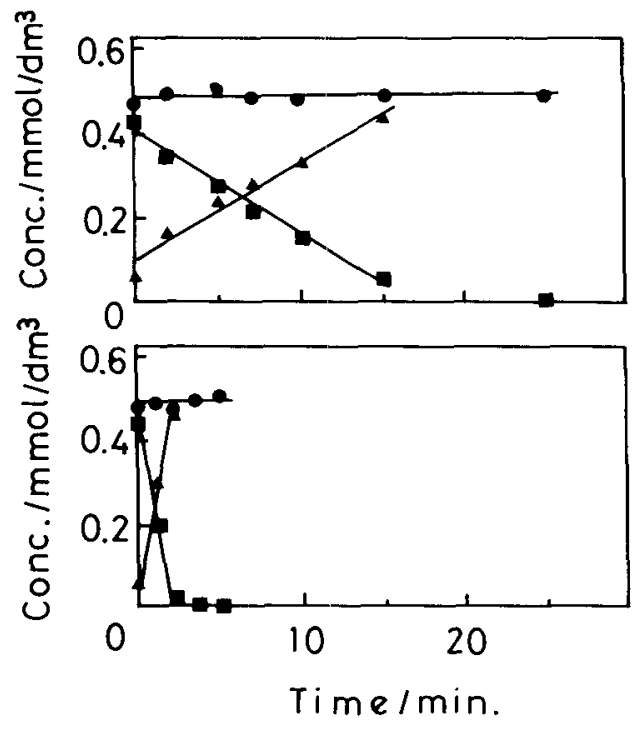

Fig. 3 Time profiles of sulfite, sulfate and their total concentration during UV irradiation in the presence of the yellow sand (upper) and iron oxide (lower); : sulfite; $\boldsymbol{\Delta}$ : sulfate; : the total.

be due to the direct photoexcitaion of sulfite anions by short wavelength light 14). The oxidation rate, however, was about one fifth that of the photocatalytic oxidation by yellow sand. These results show that sulfite anion is photocatalytically oxidized to sulfate anion with no other reactions besides sulfate production. The reaction rates per one gram of the photocatalysis are approximately $2.7 \times 10^{-7} \mathrm{~mol} \mathrm{~s}^{-1}$ for yellow sand and $1.4 \times 10^{-5} \mathrm{~mol} \mathrm{~s}^{-1}$ for iron oxide under these experimental conditions.

The results of the characterization of the yellow sand and the experiment under irradiation indicate that airborne yellow sand dust supposedly have photocatalytic activity for sulfite oxidation, i.e. acid rain formation.

Soil particles, blown up from many arid areas, covers most of the world ${ }^{15)}$ and its total amount is estimated to be 500-1900 Mt year ${ }^{-1} 16,17$ ). Although the reaction rate of photocatalysis in the presence of soil aerosol (in this study the yellow sand) is slower than that of iron oxide, it may be more substantial in the atmosphere due to the huge amount of soil aerosol, especially in regions such as Japan which are down - wind of arid areas.

Although the photocatalytic substance in the yellow sand which promote sulfite oxidation has not yet been identified, we can show several possibilities: iron-containing minerals such as feldspar may act as a photocatalyst; reoxidation of dissolved iron ion from yellow sand forms iron oxide which has been reported to photooxidize sulfite to sulfate 5). Further study of the detailed reaction mechanism is proceeding.

\section{REFERENCES}

1) N.R. Glass, G.E. Glass, and P.J. Rennie, Environ. Sci. Technol., 13, 1350 (1979).

2) J.H. Seinfeld, Atmospheric Chemistry and Physics of Air Pollution, John Willey \& Sons, New York, p. 228 (1986).

3) L.R. Martin, $\mathrm{SO}_{2}, \mathrm{NO}$ and $\mathrm{NO}_{2}$ Oxidation Mechanisms: Atmospheric Considerations (Ed. J.G. Calvert), Butter Worth Publishers, Boston, p. 63 (1984).

4) A. Rani, D.S.N. Prasad, P.V.S. Madnawat and K.S. Gupta, Atmos. Environ., 26A, 667 (1992).

5) B.C. Faust, M.R. Hoffmann and D.W. Bahnemann, J.Phys. Chem., 93, 6371 (1989).

6) Y.Hori and S. Suzuki, Chem. Lett., 1987, 1397.

7) K. Takeuchi and T. Ibusuki, Encyclopedia of Environmental Control Technology (Ed. P.N. Cheremisinoff), Vol. 2, Gulf, Houston, p. 279 (1989) and references therein.

8) K.M. Sancier and H. Wise, Atmos. Environ., 15, 639 (1981).

9) C. Kormann, D.W. Bahnemann, and M.R. Hoffmann, Environ.Sci. Tecnol., 22, 798 (1988).

10) F. Kato, M. Fujimura, F. Tanaka, Y. Sekine, 32th Annual Meeting of the Japan Society of Air Pollution, Abstr. 9206 (1991).

11) M. Uematsu, R.A. Duce, J.M. Prospero, L. Chen, J.T. Merrill, and R.L. McDonald, J. Geophys. Res., 88, 5343 (1983).

12) T. Ishizaka, S. Kanamori, N. Kanamori, M. Nishikawa, and T. Mizoguchi, Kousa (Ed. Water Research Institute, Nagoya Univ.), Kokonshoin, Tokyo, p. 109 (1991).

13) K. Isono, M. Komabayasi, and A. Ono, J. Meteor. Soc. Japan, 37, 211 (1959).

14) E. Hayon, A. Treinin, and J. Wilf, J. Amer. Chem. Soc., 94, 47 (1972).

15) J.M. Prospero, J. Geophys. Res., 84, 725 (1979).

16) J.T. Peterson and C.E. Junge, Man's Impact on the Climate (Ed. W.H. Matthews, W.W. Kellogg and G.D. Robinson), The MIT Press, Cambridge, p. 310 (1974).

17) G.A. D'Almeida, J. Clim. Appl. Meteor., 25, 903 (1986). 